\title{
Alfredo Molano: Historias de Vidas Reales
}

\author{
Por: Edgar Rey Sinning
}

engo la sensación de que cada vez que leo, o releo, una obra del
sociólogo Alfredo Molano Bravo, no sólo me acerca a una realidad
nacional que los colombianos no conocemos del todo, o no queremos conocer o mejor aún, que pareciera que no estuviéramos interesados en conocer o saber. Además, los textos de Molano, me acercan a comprender la frase contundente de Anthony Giddens, director de la London School of Economics and Political Sciences, cuando afirma que "la sociología tiene algo que provoca una irritación que no logran suscitar otras disciplinas académicas" ${ }^{1}$. Los libros de Alfredo Molano Bravo como sus columnas periodísticas, producen a algunos colombianos una irritación tal, que lo ha llevado a permanecer exiliado por largos períodos.

Los libros de Molano tienen a mi entender dos enseñanzas claves: una la metodológica, y otra la historia reciente del país. Desde lo metodológico, aprendo la importancia de una técnica, las historias de vida, esta es una herramienta importante para reconstruir la historia de la vida de la nación. Que no es otra que la vida del desplazamiento forzado, la violación de los derechos humanos, la guerra, el narcotráfico, el latifundio, el imperio de los terratenientes. En fin la historia de unos ricos que quieren ser más ricos y unos pobres que tratan de sobrevivir a los embates, no sólo de la naturaleza, sino, y sobretodo, de esos ricos. Dueños posiblemente del país.

Es eso sobrevivir en un Estado indolente generador de una violencia estructural, ancestral y que en los textos de Molano aparece con pelos y señales, desde cuando apareció en 1985 "Los años del tropel: crónicas de la Violencia" hasta el recientemente publicado por Editorial Planeta "Penas y cadenas" (2004). Miremos que nos testimonia Molano en esta obra de singular importancia para saber y conocer de las situaciones que viven los presos en las cárceles colombianas.

${ }^{1}$ GIDDENS, Anthony. En Defensa de la Sociología, Alianza, Madrid, 2000. Pág. 11

${ }^{2}$ MOLANO, Alfredo. La vida es más sencilla y a la vez más compleja. Reflexiones sobre

Hace muchos años en un evento en Mompox, nos confesó: "Mis relatos son una traducción de la vida, pero no una trascripción de las entrevistas" ${ }^{2}$. Y es esa "traducción de la vida", lo que me permite pensar que los libros de Molano nos admiten ver esas vidas de colombianos abandonados y estrangulados por el historia oral. En: "Contra el Caos de la Desmemoriación". COLCULTURA-PNRPNUD, Bogotá, 1990, Pág. 193 
3 Contracarátula del libro "Penas y Cadenas", Planeta, Bogotá, 2004. 244 págs.

${ }^{4}$ Relato "El Carcelero". Pág. 185.

${ }^{5}$ Contracarátula del libro "Penas y Cadenas".

6 "El relato de Don Pedro". Pág. 11. mismo Estado. En su reciente libro "Penas y cadenas" ratifica su vocación de traductor de vidas de colombianos. Es un libro revelador de esas vidas vividas en nuestras cárceles. Estoy convencido, como se afirma en la contra carátula, que "nunca se había escrito en el país un testimonio tan real y descarnado sobre el mundo de las cárceles" ${ }^{3}$. ¿Quién hubiera dado mejor testimonio de estas vidas, de estos hechos de la Colombia de hoy, sino Molano que ha buscado y rebuscado, para conocer esas vidas olvidadas?. Ya en sus textos anteriores nos había acercado a la otra Colombia, la de los sin tierra, a los "desterrados". En este libro ya no fue a buscar historias al Guaviare o al Llano, no fue a la vida rural. No. Se quedó en las zonas urbanas, escudriñando en las cárceles para conocer cómo viven, como funcionan esos lugares creados para la resocialización. Produce risa el lema que uno encuentra a la entrada de las cárceles: "Aquí entra el delito no el hombre". Las cárceles colombianas son definidas por "El Carcelero", en el relato quinto de su último libro: "La cárcel destroza a los seres humanos, los rebaja al escalón más bajo de la especie. No es un castigo, es un asesinato"4.

Qué distante esta frase, qué distante está ese proceso de la resocialización de la que se habla y escribe. En los seis (6) relatos de igual número de personajes, se da cuenta de esas vidas reales, de colombianos que por cualquier razón han llegado a pagar penas que se convierten en cadenas. Los autores de los relatos "cuentan con dureza, los infiernos que se han visto obligados a padecer. Los seis están en la cárcel. Los seis confiesan con una convincente sinceridad desde crímenes espeluznantes, hasta picarescas aventuras dignas de un Lazarillo de Tormes moderno" ${ }^{\prime}$. No se equivocan ni exageran en un afán propagandístico por vender el libro, los editores en la contra carátula. Hay que leer el libro para entenderlo. Uno escucha muchas cosas que suceden en las cárceles. Pero sinceramente nunca llegué a imaginar que sucedieran hechos como los "traducidos" por Molano de esa vidas condenadas a morir en el olvido, o aplicando, su propia ley.

Son seis relatos, que tratan sobre vidas condenadas en cárceles colombianas, donde se desaparecen seres vivos sin conocer razones. La primera historia se llama "El relato de don Pedro". Este personaje narra la presencia de sus compinches en la cárcel "La Modelo" de Bogotá. Miremos lo que debe ejecutar un detenido, para "demostrar que se valía por sí mismo": "El Flaco hizo las cosas como Dios manda: en silencio y sin asco. El que sabe sabe, dicen por ahí, y el hombre, no se puede negar, mostró que era un as con la hachuela. En canas serias, como La Modelo las cosas son o no son. Y si no son, se hace que sean. Es la ley"6.

De tal manera que al iniciarse el relato, se anuncia lo que va a suceder. Así sucede en "Crónica de una Muerte Anunciada": "El día en que lo iban a matar, Santiago 
Nasar se levantó a las 5:30 de la mañana..."7. Así como no fue posible salvarle la vida al personaje de Gabriel García Márquez, "El Alacrán”, sentenciado a muerte para que El Flaco demostrara quien era, tampoco tenía salvación, sobre todo por su capacidad para manejar la hachuela. Veamos que pasó: “...El Flaco le soltó el hachuelazo sin consultarle. Del primer golpe lo dejó comiendo suelo..." Hasta ahí el relato, no deja de ser una noticia de un asesinato. Pero ¿cómo desaparecer un cuerpo de una cárcel con tantos controles para entrar y salir? Continúa el relato de esa parte así: "El Flaco demostró ser un profesional. Golpe que daba trozo que separaba de tajo. Primero las piernas, largas y fuertes...en tres minutos las tenía entre costales y ya ni sangraban. Más tarde sacó el atado de brazos, mientras desangraba los entresijos: corazón, pulmones, hígado...La sangre se echó a la alcantarilla del baño, que se había destapado con Diablo Rojo..." $"$.

Después de recoger el resto del cuerpo y la cabeza del difundo y meter todo en costales, El Flaco bajó al sótano del patio Uno y llegó a un sitio que le llaman "El Quebradero", donde lo esperaban: "un tronco de madera, unos cuchillos y una piedra de amolar. Con botas de caucho y delantal verde, el hombre se dio a la tarea de picar menudo y envasar los restos del Alacrán por la tubería..." 10 Y continúa la narración, de cómo desaparecer un hombre de una cárcel. Las narraciones son tan crudas que producen una profunda tristeza sobre el sistema carcelario del país.

Cada uno de los seis relatos nos llevan a reflexionar sobre la cotidianidad de las cárceles nuestras, que están llenas de historias de vidas reales. De hombres y mujeres capaces de matar, robar o convertirse en el sexo opuesto para satisfacer las aberraciones del más fuerte como le pasó al Infante de la Marina Claudio, que "terminó de mozo de un jíbaro. Abandonó mujer y esperanzas"11.

Los otros personajes nos muestran esa dura vida en las cárceles, las luchas de los detenidos por condiciones dignas, como el relato de "Isidro". Un exguerrillero, que el día que le llegaría la boleta de libertad "murió de isquemia cerebral"12. Todos los relatos me conmovieron. En algunos casos me tocó suspender la lectura para respirar y llenarme de valor para enfrentar una lectura tan dura. En ese último relato, lloré profundamente al momento de la narración de "Laura" cuando ella descubre que el amor de su vida ha muerto, después de haberlo seguido por varias cárceles del país, solo para estar cerca de él: su amor.

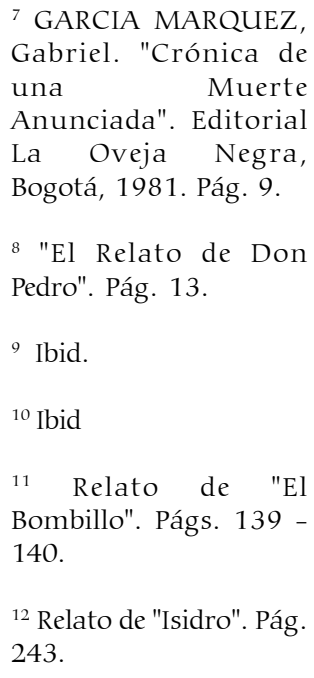

${ }^{12}$ Relato de "Isidro". Pág. 243.

Ahí está el libro, no conozco pronunciamiento de las autoridades, al menos algún comentario al respecto. Se que Molano no miente. Por lo tanto sería bueno 
Pág. 182.

saber qué piensan las autoridades carcelarias del país. Porque si lo que el libro testimonia es cierto, pienso que deben revisarse las políticas en tal sentido, de lo contrario estaríamos aceptando que "los calabozos de muerte donde se encierra a quienes se quiere que se maten entre sí"13, es una realidad. Esa es una afirmación de "El Carcelero", que era guardia y considera que "los guardias somos el producto de los presos". 